\title{
A rare case report of rupture uterus with full fetus in bladder
}

\section{Sujata Singh, Lopamudra Jena, Sujata Swain, Subhashree Rout*}

Department of Obstetrics \& Gynecology, S.C.B Medical College, Cuttack, Odisha, India

Received: 23 July 2015

Accepted: 14 August 2015

\author{
*Correspondence: \\ Dr. Subhashree Rout, \\ E-mail: drsubhashreerout@yahoo.com
}

Copyright: (C) the author(s), publisher and licensee Medip Academy. This is an open-access article distributed under the terms of the Creative Commons Attribution Non-Commercial License, which permits unrestricted non-commercial use, distribution, and reproduction in any medium, provided the original work is properly cited.

\begin{abstract}
Uterine rupture is the primary concern when a patient chooses a trial of labour after a caesarean section. Bladder rupture accompanied by uterine rupture should be taken into consideration if gross haematuria occurs. We report the case of a patient with uterine rupture during a trial of labour after cesarean delivery. Her course of labour went into obstructed labour and failed forceps delivery for which she was referred to our tertiary care hospital. Intra -operatively she was found to be a case of rupture uterus with rupture of bladder and full fetus lying in the bladder which was delivered by giving incision on the anterior bladder wall. Patient had subtotal hysterectomy with repair of bladder done with suprapubic cystostomy. Her postoperative recovery was uneventful. Bladder injury and uterine rupture can occur at any time during labour. Gross haematuria immediately after delivery is the most common presentation. The incidence of rupture uterus and associated bladder injury is on increase due to higher rates of caesarean section. But there are no case reports on full fetus inside the bladder, so it is justified to report this case.
\end{abstract}

Keywords: Rupture uterus, Obstructed labour, Failed forceps, Subtotal hysterectomy

\section{INTRODUCTION}

Uterine rupture in pregnancy is rare and often a catastrophic complication with high risk of fetal and maternal morbidity and mortality. Rupture of uterus can occur in a scarred or an unscarred uterus. The prevalence of rupture uterus tended to be lower for countries defined by the United Nations as developed than the less or least developed countries. For women with previous caesarean section, the prevalence of uterine rupture reported $1 \%$.,the risk varies according to the type and location of previous uterine incision. ${ }^{1}$ An interval less than 6 months was associated with increased risk of uterine rupture. ${ }^{2}$ Rupture uterus can involve adjacent organs most common being the urinary bladder which is an acute obstetric emergency.

\section{CASE REPORT}

A 30 years $\mathrm{G}_{2} \mathrm{P}_{1}$ at term gestation with previous caesarean section was referred to our tertiary care hospital as a case of prolonged second stage of labour with failed forceps. On examination she was conscious, oriented, afebrile, dehydrated, having moderate pallor, PR-120/min, BP-90/70 mm of $\mathrm{Hg}$, with no respiratory \& cardiovascular abnormalities. On abdominal examination there was generalised abdominal tenderness, loss of uterine contour, fetal parts felt superficially and fetal heart sounds not localised. Foleys catheter was in situ with haemorrhagic urine. On $\mathrm{P} / \mathrm{V}$ examination cervix fully effaced, os fully dilated, membrane absent with blood stained liquor coming out and head station at 0 . Suspecting uterine rupture along with bladder injury urgent laparotomy under general anaesthesia was planned 
with one unit of blood in hand. Abdomen opened by longitudinal incision. The intraperitoneal anatomy was totally distorted. Incision was given on anterior wall of bladder thinking it to be anterior uterine wall and a female dead fetus weighing $2.5 \mathrm{~kg}$ delivered [Figure 1]. It was found that bladder was bivalved as the head was entrapped completely inside the bladder cavity due to uterine rupture at previous scar site along with posterior bladder wall rupture. As uterine repair was not possible subtotal hysterectomy done by clamping, cutting and ligating the supports of uterus. Bladder was bivalved both anteriorly and posteriorly [Figure 2]. Posterior angle extended up to bladder neck. Infant feeding tubes were given in both ureteric orifice. Bladder closed in two layers by urologist. Both suprapubic and per urethral catheter given. She received one intraoperative and one post-operative blood transfusion. Except $\mathrm{Hb}(9.1 \mathrm{gm} \%)$, rest routine blood and urine reports were within normal limits. Her post op period was uneventful. Her suprapubic catheter removed on 14th post-operative day and she was discharged. She came for her first follow up on $30^{\text {th }}$ postoperative day; her urethral catheter was removed. She had no micturition difficulties \& urinary retention following that.

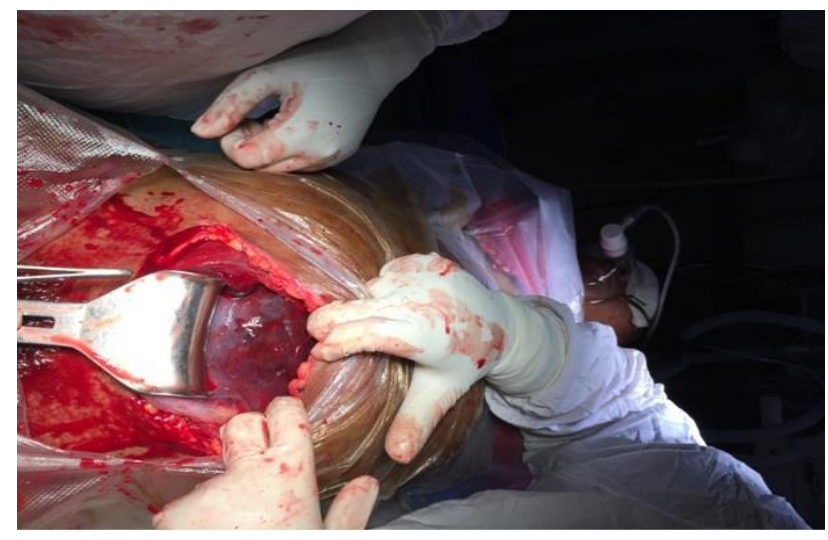

Figure 1: Distended bladder with entrapped fetal head.

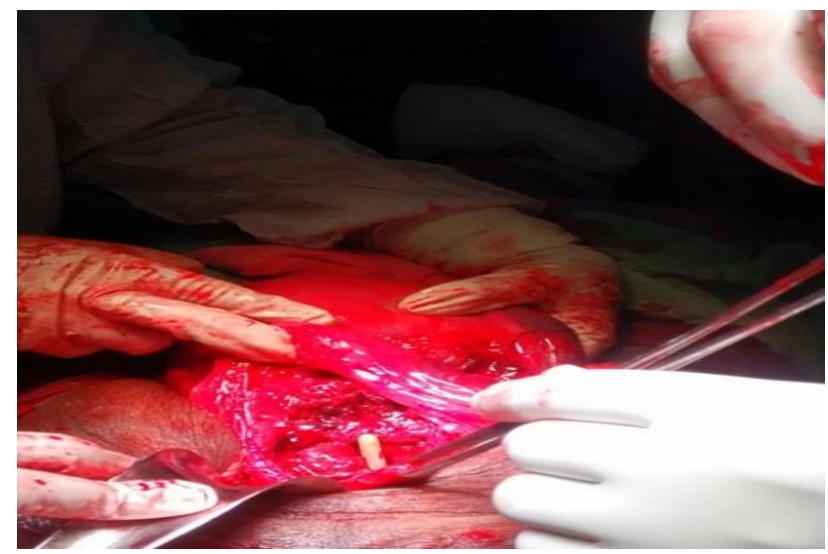

Figure 2: Bivalved urinary bladder anterior to uterus.

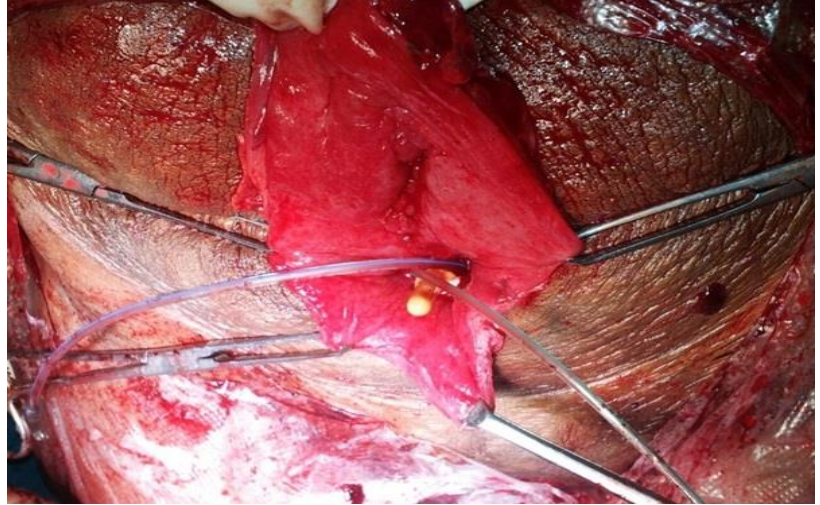

Figure 3: Repaired posterior bladder wall with two infant feeding tubes in both ureteric orifice after subtotal hysterectomy.

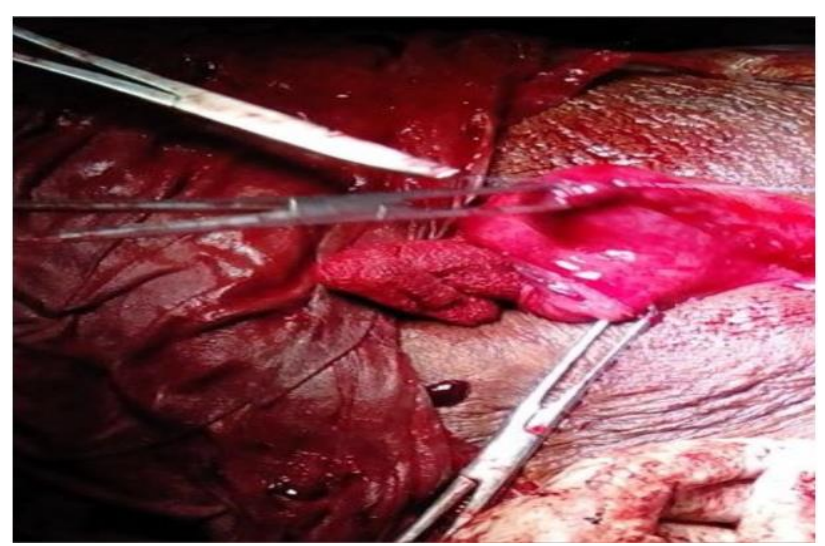

Figure 4: Repaired anterior wall of bladder.

\section{DISCUSSION}

The clinical presentations of concomitant uterine and bladder rupture at the time of VBAC are variable and depend on the time, location and type of uterine rupture that extends onto the adjacent organs. Severe signs and symptoms can result when a complete rupture occurs intrapartum, including a non-reassuring fetal heart tracing, loss of the presenting part on pelvic examination, change in uterine shape, cessation of uterine contractions, abdominal pain, vaginal bleeding, and even maternal shock. $^{4-7}$

Rupture of a previous caesarean section scar is frequently diagnosed on the basis of altered fetal heart rate pattern, vaginal bleeding, maternal tachycardia or unusual pain during labour. In most cases which occur in a hospital setting, timely laparotomy results in safe delivery of the baby and repair of the uterus. A recent review of uterine rupture limited to women with previous caesarean section in developed countries reported increased risk of uterine rupture and perinatal death for women undertaking trial of labour compared with elective repeat caesarean section. ${ }^{3}$. A major factor in uterine rupture is obstructed labour. In less and least developed countries, uterine rupture is more prevalent than in developed countries. In 
developed countries most uterine ruptures follow caesarean section. Future research on the prevalence of uterine rupture should differentiate between uterine rupture with and without previous caesarean section. In less and least developed countries, uterine rupture is an important cause of maternal mortality, accounting for as many as $9.3 \%$ of maternal deaths in one Indian study. ${ }^{8}$

For estimating the likelihood of developing rupture of a scar during subsequent labor, some investigators have suggested using sonography as a tool for evaluating the risk of VBAC. ${ }^{9,10}$ The thickness of the lower uterine segment measured by transabdominal or transvaginal sonography is correlated with the risk of rupture. ${ }^{10}$ However, the critical cut-off value for a safe lower segment thickness is controversial. Bergeron et $\mathrm{al}^{10}$ concluded that a full lower uterine segment $<2.3 \mathrm{~mm}$ in thickness measured between 35 and 38 weeks of gestation is associated with a higher risk of complete uterine rupture during VBAC. To date, there have been no isolated bladder ruptures reported in gravidas undergoing VBAC. Therefore, in addition to the criteria issued by the American College of Obstetricians and Gynecologists in 2004, measurement of the full lower uterine segment thickness may be useful to evaluate the risk of simultaneous uterine and urinary bladder rupture.

The management of uterine and bladder rupture usually requires laparotomy because of fetal distress or an arrest of labor. ${ }^{11-14}$ In VBAC patients, rupture results from traumatic separation of the dense adhesions between the uterus and bladder during labor. Thus, expectant management might result in poor healing, which in turn could lead to the formation of vesicouterine fistulas. Once suspected, cystoscopy should be performed to identify the bleeding source and possible bladder and uterine rupture. In addition to uterine rupture, the possibility of bladder injury should be included in the patient's antepartum counseling for VBAC. Careful selection of candidates for a trial of labor is the most important issue to prevent an unwanted outcome.

\section{CONCLUSION}

The high maternal morbidity, mortality and fetal mortality that follow uterine rupture calls for an integrated effort to prevent its cause. Good antenatal care, early diagnosis of high risk obstetric cases, timely referral, and availability of transportation, increased patients awareness on birth spacing can help us curtail this problem of increased maternal mortality and morbidity due to rupture uterus and rupture bladder.

Funding: No funding sources Conflict of interest: None declared Ethical approval: Not required

\section{REFERENCES}

1. WHO systematic review of maternal mortality and morbidity: The prevlence of uterine rupture. BJOG: An International Journal of Obstetrics and Gynaecology. 2005;112:1221-8.

2. Stamilio DM, DeFranco E, Pare E, Odibo AO, Peipert JF, Allsworth JE. et al. Short interpregnancy interval: risk of uterine rupture and complications of vaginal birth after cesarean delivery. Obstet Gynecol. 2007;110:1075-82.

3. Guise J-M, McDonagh MS, Osterweil P, Nygren P, Chan B, Helfand M. Systematic review of the incidence and consequences of uterine rupture in women with previous caesarean section. BMJ2004;329:1-7.

4. Quilligan EJ. Vaginal birth after cesarean section: 270 degrees. J Obstet Gynaecol Res. 2001;27:16973.

5. Rageth JC, Juzi C, Grossenbacher H. Delivery after previous cesarean: a risk evaluation. Obstet Gynecol. 1999;93:332-7.

6. McMahon MJ. Vaginal birth after cesarean. Clin Obstet Gynecol. 1998;41:369-81.

7. Yap OWS, Kim ES, Laros RK. Maternal and neonatal outcomes after uterine rupture in labor. Am J Obstet Gynecol. 2001;184:1576-81.

8. Rajaram P, Agarwal A, Swain S. Determinants of maternal mortality: a hospital based study from South India. Indian J Matern Child. 1995;6(1):7-10.

9. Smith JG, Mertz HL, Merrill DC. Identifying risk factors for uterine rupture. Clin Perinatol. 2008;35:85-99.

10. Bergeron ME, Jastrow N, Brassard N, Paris G, Bujold E. Sonography of lower uterine segment thickness and prediction of uterine rupture. Obstet Gynecol. 2009;113:520-2.

11. Kattan SA. Maternal urological injuries associated with vaginal deliveries: change of pattern. Int Urol Nephrol. 1997;29: 155-61.

12. Popli K, Puri M, Gupta A. Cord prolapse though the urethra. Aust N Z J Obstet Gynaecol. 2002;42:413.

13. O'Grady JP, Prefontaine M, Hoffman DE. Vernixuria: another sign of uterine rupture. J Perinatol. 2003;23:351-2.

14. Gupta A, Chauhan M, Dahiya P, Sangwan K. Meconium stained urine: an unusual sign of combined uterine and bladder rupture. Aust N Z J Obstet Gynaecol. 2005;45:334.

Cite this article as: Singh S, Jena L, Swain S, Rout $S$. A rare case report of rupture uterus with full fetus in bladder. Int J Reprod Contracept Obstet Gynecol 2015;4:1607-9. 